\title{
Adsorption of radioactive elements on alumina and its uses for determination of gross $\alpha$ activity in urine
}

\author{
M. B. HAFEZ, A. F. NAZMY and M. M. ELDESOKY
}

Manuscrit reç le 10 mai 1977.

RÉSUMÉ

\begin{abstract}
On a vérifié l'adsorption sur l'alumine de certains produits de fission et de certains actinides en solution aqueuse et en présence de phosphates. L'étude de l'adsorption en fonction du $\mathrm{pH}$, de la force ionique et de l'àge du radionucléide indiquent le rỏle considèrable de ces paramètres dans l'interaction entre le radionuclèide et la surface de l'alumine. On donne une mèthode, basée sur les phénomènes d'adsorption des actinides sur l'alumine, qui permet d'évaluer l'activité $\alpha$ globale dans l'urine.
\end{abstract}

\section{ABSTRACT}

Adsorption of some fission product and actinide elements, from aqueous and phosphate solutions on alumina surface was verified. Studies of adsorption as a function of $\mathrm{pH}$. ionic strength, and age of radionuclide indicated that these variables strongly acted on the interaction between the radiocuclide and alumina surface. A method based on the adsorption phenomenon of actinide elements on alumina was developed in order to determine gross $\alpha$ activity in urine.

\section{INTRODUCTION}

The theory and practice of inorganic adsorbents have been advanced to such a degree that they can be now regarded as one of the established methods for the study of adsorption of trace elements on surfaces. Alumina is a material

(*) Radiation Protection Department. Atomic Energy Establishment. Cairo, Arab Republic of Egypt. 
of particular interest because it can be used to separate hydrogen isotopes [1] and cis - trans isomers of organic compounds [2].

The adsorption properties of alumina have been compared by DOBYCHIN [3], with those of known adsorbents such as microporous glass and silica. The polarity of the surface and the uniform porosity of alumina ensure high efficiency. Deviations from these patterns would be expected in case of fixation of charged particles through alumina. Adsorption of these cations on alumina seems to occur under certain chemical conditions such as $\mathrm{pH}$, concentration, hydrolysis state of the element and its age. In the present study, the adsorption behaviour of low level activity of ${ }^{144} \mathrm{Ce},{ }^{60} \mathrm{Co},{ }^{90} \mathrm{Sr},{ }^{137} \mathrm{Cs},{ }^{235} \mathrm{U},{ }^{232} \mathrm{Th},{ }^{239} \mathrm{Pu}$ and ${ }^{241} \mathrm{Am}$ on alumina has been investigated and a method for the determination of gross $\alpha$ activity in urine is proposed.

\section{MATERIALS AND METHODS}

\section{Materials}

All chemicals were of analytical grade. ${ }^{144} \mathrm{Ce},{ }^{60} \mathrm{Co},{ }^{137} \mathrm{Cs},{ }^{90} \mathrm{Sr},{ }^{232} \mathrm{Th},{ }^{235} \mathrm{U}$, ${ }^{239} \mathrm{Pu}$, and ${ }^{241} \mathrm{Am}$ were in the valency state of $\mathrm{Ce}$ (III), Co (II), $\mathrm{Cs}$ (I), $\mathrm{Sr}$ (II), Th (IV), U (VI), Pu (IV) and Am (III). Reduction processes were carried out by using sodium sulphite solution while oxidation processes were done by ammonium persulphate solution.

The alumina had particle size 80 mesh. The alumina was loaded in a column ( $1 \mathrm{~cm}$ diameter) to give a height of $5 \mathrm{~cm}$. The column had a $250 \mathrm{ml}$ capacity reservoir and the alumina was supported on glass wool plug.

The pHmeter of type, O. p. 401/1, was used to measure the pH of solutions. $\beta$-activity was measured by an end-window G.-M. counter, while $\alpha$ sources were counted by $\mathrm{ZnS}$ scintillation counter (detection limit being $0.03 \mathrm{pCi}$ ).

\section{Procedure}

\subsection{Fixation of radioactive elements from aqueous solution}

Groups of ten solutions of $100 \mathrm{ml} \perp \mathrm{N} \mathrm{HNO}_{3}$, were respectively spiked with one of the radioactive elements (each solution contained approximately $2.5 \times 10^{-4} \mu \mathrm{Ci}$ ). The solutions were adjusted to a $\mathrm{pH}$ range 0.5 to $10 \mathrm{using}$ $1 \mathrm{~N} \mathrm{NH}_{4} \mathrm{OH}$ solution. Each solution was passed through the alumina column.

The fixed quantity of the radionuclide, at a certain $\mathrm{pH}$, was removed from the column by $30 \mathrm{ml}$ of $5 \mathrm{~N} \mathrm{HCl}$. Then the column was washed by $20 \mathrm{ml}$ of $\mathrm{H}_{2} \mathrm{O}$. The effluent and the eluent acid solutions were evaporated to a small volume and quantitatively transfered to a clean watch glass of $3 \mathrm{~cm}$ diameter. The percentage of fixed and non-fixed radioelement on alumina, at each $\mathrm{pH}$, was calculated by comparison with the same radioelement initially spiked.

To study the effect of the age of radioelement at different $\mathrm{pH}$, four groups of ten solutions of $100 \mathrm{ml} 1 \mathrm{NHNO}_{3}$ were spiked with the radionuclide. The 
solutions were adjusted to a $\mathrm{pH}$ range from 0.5 to 10 using ammonia. The solutions were stored for 5, 60, 180 and $360 \mathrm{~min}$ after the preparation and before passing it through the column. Elution was done by $30 \mathrm{ml}$ of $5 \mathrm{~N} \mathrm{HCl}$. The percentage of fixed and non-fixed radioelement, at each $\mathrm{pH}$ and at a certain age, was then calculated as above.

\subsection{Fixation of radioactive elements from phosphate solution.}

In order to study the effect of phosphate ions on adsorption, these series of experiments were repeated using solutions contaminated with the radionuclide and $300 \mathrm{mg}$ of calcium phosphate. The $\mathrm{pH}$ was adjusted to a range from 0.5 to 6.2 (at $\mathrm{pH}>6.5$ phosphate ion precipitates). Elution was done using $30 \mathrm{ml}$ of $\mathrm{HCl} 5 \mathrm{~N}$. The percentage of fixed and non-fixed radioelement on alumina, at each $\mathrm{pH}$, was then calculated as above.

\section{RESULTS AND DISCUSSION}

Preliminary experiments indicated that fixation of radioelement on alumina and its elution from it, were completely independent of the flow rate. The optimum acid concentration and volume needed for complete removal of the radioelement from alumina was found to be attained with $30 \mathrm{ml}$ of $0.5 \mathrm{~N} \mathrm{HCl}$. Experiments were also carried out to determine the capacity of retention for cerium at $\mathrm{pH}=5$. The results showed that the capacity was equal to $0.38 \mathrm{meq} / \mathrm{g}$.

\section{Fixation of radioActive elements from aqueOus SOlution}

Figure 1 represents the variation of the percentage of radionuclide fixation as a function of $\mathrm{pH}$. Fixation on alumina was highest at $3<\mathrm{pH}<6.5\left({ }^{60} \mathrm{Co}\right.$ was fixed at $\mathrm{pH}>5.5$ ). GRABENSCHCHIKova and DAvYdov [4] showed that up to $\mathrm{pH}$ of about 7.5 colloidal plutonium particles possess a positive charge. Similar results have been quoted by Kraus [5] for U (IV) and U (VI), Th (IV), Am (III), and Ce (III). On the other hand, since the charge on the alumina surface is always negative above a $\mathrm{pH}$ of about 2 [6], it is possible to postulate adsorption of the radioelements on alumina, at $3<\mathrm{pH}<6.5$; this is due to the formation of positively soluble hydrolysed species, of the element at such $\mathrm{pH}$, which could be attracted on the negatively charged alumina surface. According to VOLD [7], the major force are long range Van der Waal's forces of attraction and electrical double layer interaction.

Figure 1 shows that at $\mathrm{pH}>6.5$ and at $\mathrm{pH}<3$, the percentage fixation of the radionuclides decreased with $\mathrm{pH}$. A number of effects may be responsible, such as a change in the structure of the alumina, or a change of the state of the ion in solution, or alteration in binding properties of the active groups. Above pH 8 the charge on the particles Ce (III), Co (II), Th (IV), U (VI), Pu (IV), and Am (III) became negative as the hydroxyle ion concentration increased [8]. Since the charge on the alumina is always negative, there should be a net repulsion 
between the alumina surface and the radioelement particles. Increasing of the $\mathrm{OH}^{-}$ion concentration maintained and increased this negative charge, resulting in reduced adsorption on alumina. At $\mathrm{pH}<3$ adsorption decreased as shown in fig 1. The higher the acidity of the medium the lower the adsorption. This is due to competition between hydrogen ions and the metal ion to be adsorbed on alumina [9].

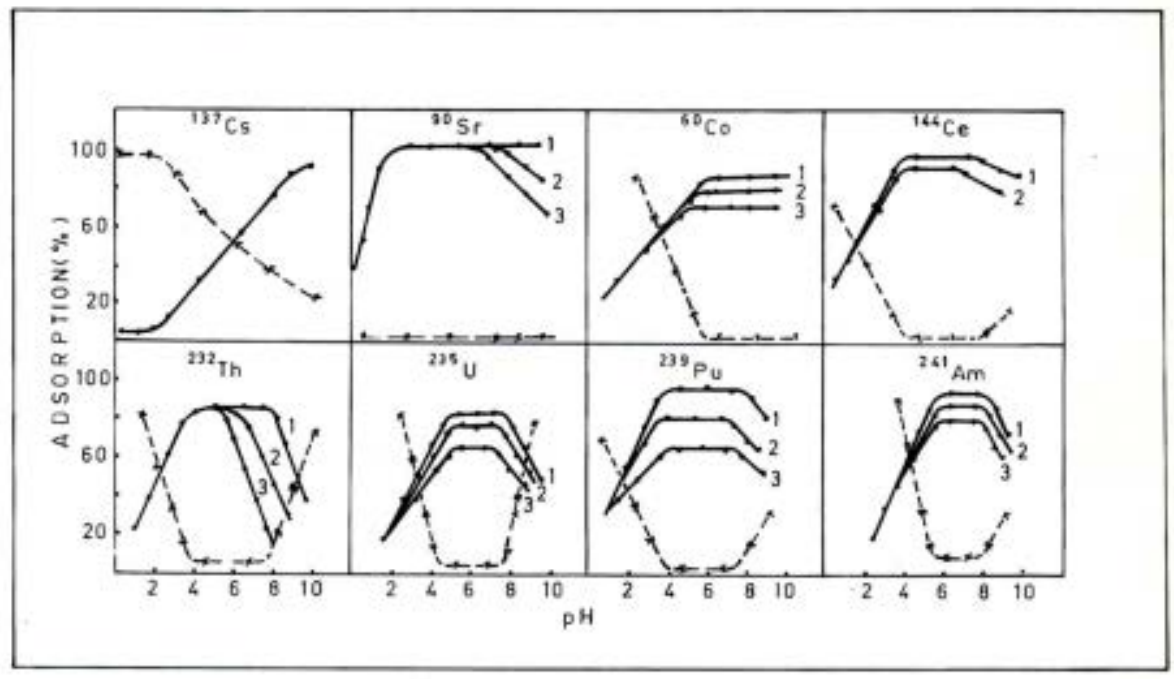

FiG. 1. - Variation of percentage of adsorption of different radionuclides, from aqueous solutions, at different age times $\mathrm{T}$, as a function of $\mathrm{pH}$ ( $\mathrm{T}$ is the time after adjusting the $\mathrm{pH}$ ). I. $\mathrm{T}=5 \mathrm{~min} ; 2 . \mathrm{T}=60 \mathrm{~min} ; 3 . \mathrm{T}=180 \mathrm{~min} ; 4 . \mathrm{T}=360 \mathrm{~min}: \ldots+$. Eluent; $\times \ldots \times$ Effluent.

Results in Figure 1 also show that the percentage fixation decreases as the age of the radioelement solution increases and for the same solution it decreases as the $\mathrm{pH}$ of solution increases. OKENDEN and WELCH [10] felt that ageing of Pu (VI), Am (III), Ce (III), and U (VI) solutions, at different $\mathrm{pH}$, causes a change in the charge versus size ratio of the particles. Aged particles are being larger and less charged. Variation of charge would cause a variation in the force of attraction or repulsion between the radioelement particle and the alumina surface. One may assume that the decrease in adsorption, as the age of the particle increases, is due to the disappearance, from solution, of small positively charged particles as these combine to form negatively charged colloids, which due to their negative charge are repelled by the alumina surface.

\section{FIXATION OF RADIOACTIVE ELEMENTS FROM PHOSPHATE SOLUTION}

Figure 2 illustrates the variation of the percentage of fixation of the radioelement, in phosphate medium, as a function of $\mathrm{pH}$. When phosphate ion was added to a fresh radioelement solution, at different $\mathrm{pH}$, the adsorption 
at $\mathrm{pH}<3$ decreased more than in the aqueous phase. According to DeNOTKINA et al., the formation of the phosphate complex increases the average negative charge of the ionic or colloidal radioelement species [11]. This should reduce adsorption onto negatively charged alumina surface. The formation of the phosphate complex is not expected to take place readily at $\mathrm{pH}>4$. The increase of adsorption in phosphate solution at $\mathrm{pH}>4$ is probably due to the deformation of phosphate complex. Cesium, in presence of calcium phosphate was not adsorbed to any significant extent. This was expected as it forms a soluble hydroxide.

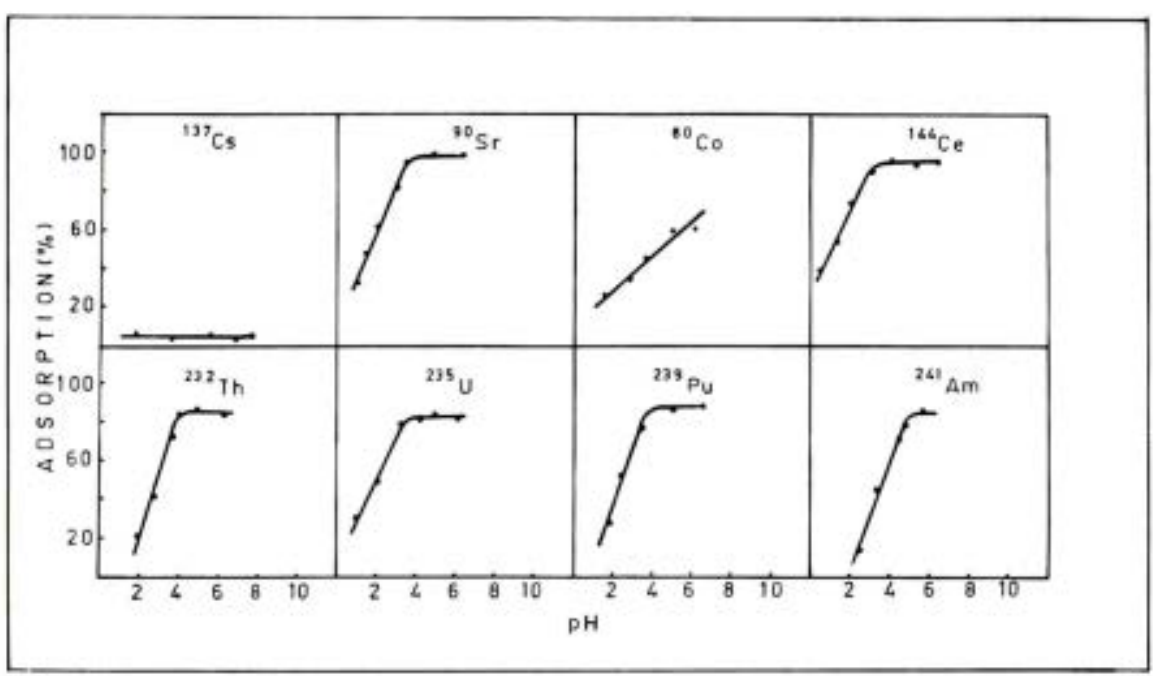

FIG. 2. - Variation of the percentage of adsorption of different radionuclides, from phosphate solutions, as a function of $\mathrm{pH}$ ( $\mathrm{T}=5 \mathrm{~min})$.

\section{DETERMINATION OF GROSS $\alpha$ ACTIVITY IN URINE}

The work described now demonstrates that co-precipitation of some fresh radioelements on phosphate ions followed by adsorption at $\mathrm{pH}=5 \pm 0.5$ on alumina is a good basis for determination of gross $\alpha$ activity in urine [12].

Groups of six $1,500 \mathrm{ml}$ urine samples were used. Each group was spiked with one of the following radionuclides: thorium, uranium, plutonium, americium, and cerium: cobalt was tested also. The samples were heated in presence of $200 \mathrm{ml}$ conc. $\mathrm{HNO}_{3}$ for three hours, in order to destroy organic compounds present in urine and obtain the radionuclide in the form of cation i. e. non-hydrolysed. Then the phosphates were precipitated by concentrated ammonia. Each precipitate was then heated in muffle furnace until pure white residue was obtained. The precipitate was dissolved in $50 \mathrm{ml}$ of $1 \mathrm{~N} \mathrm{HNO}_{3}$ and $\mathrm{pH}$ adjusted to $5.0 \pm 0.5$ with ammonia. The solution was then immediately 
passed through the alumina column. The elution was done using $30 \mathrm{ml}$ $\mathrm{HCl} 2 \mathrm{~N}$. The percentage of adsorption was then calculated by comparison with the same radionuclide initially spiked. Results are given in table I.

TABLE 1

OVERALL. RECOVERIES $(\%)$ From $1,500 \mathrm{ml}$ URINE SAMPLES ON ALUMINA SURFACE

\begin{tabular}{|c|c|c|c|c|c|}
\hline \multirow{2}{*}{$\begin{array}{l}\text { Number of } \\
\text { experiments }\end{array}$} & \multicolumn{5}{|c|}{ Element } \\
\hline & Thorium & Uranium & Plutonium & Americium & Cerium \\
\hline $\begin{array}{l}1, \ldots \ldots \ldots \\
2 \ldots \ldots \ldots \\
3 \ldots \ldots \ldots \\
4 \ldots \ldots \ldots \\
5 \ldots \ldots \ldots \\
6 \ldots \ldots \ldots\end{array}$ & $\begin{array}{l}86.10 \\
85.70 \\
91.30 \\
89.80 \\
90.20 \\
88.05\end{array}$ & $\begin{array}{l}85.20 \\
85.10 \\
86.60 \\
90.20 \\
86.20 \\
88.40\end{array}$ & $\begin{array}{l}92.10 \\
89.20 \\
93.20 \\
86.40 \\
87.30 \\
91.10\end{array}$ & $\begin{array}{l}83.30 \\
84.20 \\
94.80 \\
81.60 \\
78.40 \\
82.30\end{array}$ & $\begin{array}{l}92.40 \\
95.20 \\
94.80 \\
96.40 \\
91.80 \\
93.80\end{array}$ \\
\hline Total........ & 88.62 & 86.95 & 89.97 & 83.170 & 94,07 \\
\hline
\end{tabular}

As it can be seen, the method gives good recoveries for thorium ( 85 p. cent \pm 3 ) uranium, plutonium, americium, and also cerium. Advantages of this method over other published ones are easy handling, cheapness, and speed.

\section{REFERENCES}

[1] Shipman G. F. Separation of hydrogen isotopes by alumina. Anal. Chem., 1962, 34, 877.

[2] List G. R.. Hoffman R. T., Evans C. D. Separation of cis-trans-isomers of organic compounds by alumina. J. Am. Oil. Chemist's Soc, 1965, 42, $166 \mathrm{~A}$.

[3] Dobychin D. P.. Porshneva N. V., Turkeltaub N. M. Absorption properties of alumina. I. Appl. Chem. U.S.S.R., 1962, 35, 1202.

[4] Grenenschchikova V. L., Davydov Yu. P. État du Pu (IV) en solution 2, 10-5 M dans l'intervalle de $\mathrm{pH} \mathrm{1-12,} \mathrm{Radiokhimiya,} \mathrm{1965,} \mathrm{7,} 191$.

[5] Kraus K. A. Hydrolytic behaviour of the heavy elements, 1st. Intern. Conf. Peaceful Uses of Atomic Energy, 1955, 7, 245.

[6] KisfleV A. V., YAshin Y. I. The isoelectric points of solid oxides and aqueous hydroxocomplex system. Russ. I. phys. Chem., 1963, 37, 1414.

[7] Vot. J. M. The effect of adsorption on the Van der Waals interaction of spherical colloidal particles. J. Coll. Sci., 1961, 16, I.

[8] Kruyt H. B. Coagulation theory. J. Coll. Sci.., 1961, 16, 1.

[9] HafEZ M. B., SAlEd F. L. A. Fixation of radioactive elements on dextran gel Sephadex. J. Radioanal. chem., 1975, 25, 255.

[10] Okenden D. W., Welch G. A. The preparation and properties of some Pu compounds, Part V. J. Chem, Soc., 1956, 653, 3358.

[11] Denotkina R. G., Moskvin A. 1., Schevchenko, V. E. The composition and dissociation constants of phosphate. Russ. J. Inorg. Chem. (Engl. Transl.), 1969, 5, 731.

[12] HAFEZ M. B., SAIFD F. I. A. Determination of gross activity from urine using dextran gel Sephadex. Intern. J. Appl. Radiat. Isot., 1973, 24, 241. 